\title{
Una biografía cultural de los pueblos rurales turísticos
}

\author{
Cecilia Pérez Winter ${ }^{1}$ \\ Universidad de Buenos Aires \\ Consejo Nacional de Investigaciones Científicas y Técnicas \\ @ [ cecipw@gmail.com ]
}

RECIBIDO 09-05-2021

ACEPTADO 19-08-2021

Cita sugerida: Pérez Winter, C. (2021). Una biografía cultural de los pueblos rurales turísticos. Revista Huellas, Volumen 25, № 2, Instituto de Geografía, EdUNLPam: Santa Rosa. Recuperado a partir de: http://cerac.unlpam.edu.ar/ index.php/huellas

DOI: http://dx.doi.org/10.19137/huellas-2021-2518

\begin{abstract}
Resumen
Desde la crisis del campo, a fines de los '90 y comienzos del 2000, diversos actores estatales y no estatales han buscado dinamizar social y económicamente los pueblos rurales de Argentina. En este marco, el turismo es cada vez más frecuente en las iniciativas y programas como estrategia de revitalización ponderando los aspectos positivos del mismo. Sin embargo, el proceso conlleva una serie de transformaciones materiales y simbólicas que pueden generar tensiones. En este artículo proponemos analizar de forma crítica cómo se generan estos procesos mediante la construcción de una "biografía cultural". Esta propuesta nos permite indagar y contextualizar las implicaciones de la turistización de estos lugares.
\end{abstract}

Palabras clave: Pueblos rurales; turismo; revitalización; tensiones

\begin{abstract}
Since the crisis with the agriculture and livestock sector, which took place in the late 1990s and early 2000s, various state and non-state actors have tried to stimulate, socially and economically, rural towns in Argentina. In this context, tourism is becoming increasingly frequent in initiatives and programs as a revitalization strategy, considering its positive aspects. However, the tourism development process entails a number of material and symbolic transformations that can provoke tensions. Hence, in this article we propose to critically analyze how these processes are generated through the construction of a "cultural biography". This proposal allows us to investigate and contextualize the implications of tourism in rural towns.
\end{abstract}

Keywords: Rural towns; tourism; revitalization strategies; tensions 
Uma biografia cultural dos povos rurais turísticos

\begin{abstract}
Resumo
Desde a crise do campo no final da década de 90 e começos de 2000, diversos atores estatais e não estatais procuraram dinamizar social e economicamente os povos rurais da Argentina. Neste contexto, o turismo é cada vez mais frequente nas iniciativas e programas como estratégia de revitalização considerando seus aspectos positivos. Porém, o processo implica uma série de transformações materiais e simbólicas que podem gerar tensões. Neste artigo, propomos realizar de forma crítica como se geram estes processos a través da construção de uma "biografia cultural". Esta proposta permite indagar e contextualizar as implicações turísticas destes lugares.
\end{abstract}

Palavras-chave: Povos rurais; turismo; revitalização; tensões

\title{
Introducción
}

En estas últimas dos décadas en América Latina, y otros países europeos, se vienen planteando una serie de discusiones en torno a la valorización de lo rural. Estos procesos de revitalización están asociados a una serie de transformaciones materiales y simbólicas de estas geografías a partir de diferentes formas de entender las "nuevas ruralidades", las cuales se caracterizan, por ejemplo, por la reestructuración de las actividades agrarias, la expansión del agronegocio, los diferentes usos del suelo, una diversidad de sujetos, procesos de activaciones turístico-patrimoniales (Castro y Zusman, 2016). En este marco, nos interesa destacar el último punto en la cual determinados actores ponen en valor paisajes agrarios, lugares, saberes y prácticas socio-culturales vinculadas al campo (formas de producir alimentos, recetas, festejos, entre otros). En este contexto, ciertos elementos pasan a ser resignificados como patrimonios culturales ${ }^{2}$, como atractivos/destinos turísticos o ambas cosas. Estos procesos de valorización de lo rural desde iniciativas turístico-patrimoniales también son procesos que agregan valor mediante diferentes estrategias: certificaciones de origen y calidad o a partir de declaratorias de patrimonialización. Así, lugares, prácticas y objetos son resignificados pero también pueden adquirir nuevos usos, funciones y sentidos (Zusman y Pérez Winter, 2018).

En Argentina, a fines de los '90 y comienzos del 2000, diversos actores estatales han buscado dinamizar social y económicamente los pueblos rurales $^{3}$ mediante iniciativas como: Raíces (Secretaría de Turismo de Nación y Secretaría de Agricultura, Ganadería, Pesca y Alimentos, 2000); Mi pue- 
blo (Ministerio del Interior, 2004) o Pueblos con Almas (Cámara Argentina de Turismo Rural y Cámara de la Mediana Empresa, 2015). Asimismo, en provincia de Buenos Aires, área que venimos investigando desde el 2012, encontramos ejemplos provenientes desde las comunidades locales como la conformación de: actividades ocio-recreativas, como celebraciones y valorización de prácticas y saberes locales (Ratier, 2009); artísticas (Fernández, 2017); o a partir de la organización de encuentros e instituciones (Pérez Winter, 2019). A su vez, de manera reciente, podemos mencionar programas ${ }^{4}$ como: Pueblos Auténticos (en su momento Secretaría de Turismo de Nación, 2017), Pueblos Turísticos en provincia de Buenos Aires (Secretaría de Turismo, 2008) o Lugares mágicos en la provincia de Salta (Secretaría de Turismo, 2018). Sin embargo, no todos los pueblos resultan potenciales para el desarrollo turístico. El identificar los pueblos rurales como turísticos, un cambio de adjetivación tan simple, trae consigo una serie de transformaciones simbólicas y materiales -algunas asociadas a la mercantilización del lugar- que son necesarias reconocer, examinar y discutir para dar cuenta a quiénes y cómo está impactando el turismo. En este artículo nos proponemos, mediante la construcción de una "biografía cultural"5" (Kopytoff, 1991), analizar el proceso de turistización de los pueblos y sus implicaciones. Para ello, utilizaremos como caso empírico el pueblo de Azcuénaga, localizado en el municipio de San Andrés de Giles, provincia de Buenos Aires. Las informaciones presentadas y discutidas en este trabajo son producto de trabajos de campo realizados durante la investigación postdoctoral entre los años 2017-2018, en el que se realizó observación participante, entrevistas semiestructuradas a funcionarios vinculados al área de turismo y a pobladores de Azcuénaga. Estas informaciones se complementaron con el análisis de publicaciones (tesis, artículos, libros de historia local) y documentos (informes, normativas, código de ordenamiento territorial, folletos) consultados en archivos locales.

\section{Hacia una "biografía cultural" de los pueblos rurales}

Kopytoff (1991) señala que para que una "cosa" se torne mercancía, ésta no solo debe tener valor de uso y de cambio, sino que, además, y coincidiendo con Mary Douglas y Baron Isherwood ([1979] 1990), deben ser individualizadas y estar "marcadas culturalmente como un tipo particular de cosa" (Kopytoff, 1991; p. 89) por determinados actores. Ello implica que existe una selección orientada, no solo por aspectos relacionados a lo económico (formas de comercialización, intercambio), sino también cultural, ya que una misma "cosa" puede ser percibida diferencialmente dependiendo el contexto socio-cultural en el que se produce, utiliza e intercambia. En el caso de la turistización ${ }^{6}$, los actores que suelen tener mayor 
poder de marcación son aquellos que se identifican como "expertos", porque son quienes poseen una "voz autorizada" para determinar qué es importante, significativo y por lo tanto, que vale la pena activar turísticamente (Pérez Winter, 2018). En el caso de un pueblo, entre los criterios que se utilizan para la "marcación" -por ejemplo, desde los programas estatales como Pueblos Turísticos en provincia de Buenos Aires- se suele evaluar si el mismo posee: una mínima infraestructura para recibir visitantes, cierta accesibilidad, que cuente con algún elemento significativo que motive a las personas trasladarse hasta allí para conocerlo. En este marco, el pueblo es "marcado culturalmente" por algún atributo/característica, como el paisaje que lo rodea, su arquitectura u otras edificaciones prácticas, saberes que tienden a identificarse como sus patrimonios locales, etc. Entre esas características se va configurando su singularidad ${ }^{8}$ para destacarse dentro del mercado turístico.

Siguiendo a Kopytoff, la identificación de una "cosa" (o lugar) como mercancía (turística) implica: una descontextualización y recontextualización al despojarla de su primera "identidad" para adquirir una nueva. Así, la mercancía comienza a ser poseída o apropiada por una/s persona/s o una entidad obteniendo otro estatus, en las que se establecen nuevas formas de relación entre la "cosa/mercancía" y las personas (consumidores), produciéndose, además, otras formas de circulación. En este marco, un pueblo "marcado" o -identificado como atractivo turístico-, también pasa por un proceso de recontextualización. La "identidad" de pueblo como lugar de residencia de sus pobladores -caracterizado por ciertos valores, sentidos de pertenencia, comportamientos, versiones de pasado, personalidades y otros sujetos locales, junto a sus comercios, servicios, lugares de esparcimiento, prácticas, edificaciones y objetos- pasará a incluir otra "identidad" mediante su configuración como pueblo turístico, lo que implicará que varios de sus elementos sean resignificados, reapropiados (Massey, 1994, 1995; Prats, [1997] 2004) y refuncionalizados (Santos, [1988]2014). Estos procesos suelen ir acompañados por la construcción -desde determinados actores- de nuevas representaciones turísticas (Hiernaux Nicolás, 2002) del pueblo y su comunidad. Asimismo, para realizar una "biografía cultural" de la cosa-mercancía (pueblo-atractivo) Kopytoff (1991) señala que deben reunirse una serie de informaciones. La suma de historias vitales de la "cosa" son las que posibilitan configurar un modelo biográfico dando cuenta de las diversas trayectorias que pudieron presentarse. Para ello, reformulamos algunas preguntas guía que Kopytoff propuso para las "cosas" planteando las siguientes para el caso de los pueblos: ¿Cuándo se inició -y de qué manera- el proceso de conformación del pueblo? ¿Qué etapas y periodos productivos, sociales, económicos, históricos pueden identificarse? ¿Qué procesos, eventos, políticas y pro- 
yectos significativos tuvieron lugar? ¿Cómo han repercutido o impactado -y cuándo- en la configuración del pueblo? ¿Ello implicó transformaciones en el uso y función del asentamiento en su totalidad o en su parcialidad? ¿Cuál es la situación actual? Estas interrogantes nos permiten introducir la cuestión turística: ¿Cómo y cuándo comenzó a desarrollarse el turismo? ¿Qué elementos, características se seleccionaron para "marcar" al pueblo turísticamente? ¿Se pueden identificar etapas de ese proceso? ¿Quiénes y cómo participaron? Estas interrogantes nos permiten indagar en los sucesivos cambios que pudo haber tenido un pueblo y entre ellos: ¿por qué en algunos se incorpora/ó el turismo?, ¿qué implicaciones tuvo?, ¿qué tensiones genera/ó?, por ejemplo. Con este enfoque presentado nos proponemos analizar cómo un pueblo comienza a ser "marcado culturalmente" para configurarse como lugar turístico e identificar y analizar qué se mercantiliza y de qué manera.

\section{Una biografía cultural de Azcuénaga}

Azcuénaga se encuentra en el municipio de San Andrés de Giles, hacia el norte de la provincia de Buenos Aires, a unos $110 \mathrm{~km}$-aproximadamente- de la Ciudad de Buenos Aires - por ruta nacional 7- y unos 168 $\mathrm{km}$ de la ciudad de La Plata (Figura $\mathrm{N}^{\circ} 1$ ). Actualmente, cuenta con unos 300 habitantes de un total aproximado de 22.300 que tiene el municipio (https://www.sanandresdegiles.gob.ar/). Pertenece a la zona agrícola-ganadera del norte bonaerense y sur santafesino y forma parte de la Cuenca de Abasto de Lácteos a Buenos Aires. El área, en la que se incluyen las tierras donde se asentó el pueblo de Azcuénaga, había sido habitada por grupos móviles de cazadores-recolectores y grupos indígenas (Tarragó, 2004) que, con la ocupación de los españoles en siglo XVI padecieron un proceso violento de desposesión y desplazamiento que incidió significativamente en su forma de vida. Posteriormente, con la creación de la categoría de "merced de tierras", estas tierras se fueron repartiendo -y traspasando- desde el siglo XVII (Garavaglia, 2009) desdibujándose los orígenes de los primeros ocupantes. A estos procesos -de despojo, construcción y establecimiento de fortines para las avanzadas del territorio nacional- les siguieron otros. Entre ellos, el establecimiento de estancias -que además de funcionar también como avanzadas, fueron reflejo de la acumulación de tierras y la expansión ganadera-; la extensión de las redes ferroviarias, representando formas de industrialización mediante el transporte y la comunicación; la creación de otros centros de producción y explotación de recursos. En estos diversos procesos -que reflejan la historia de consolidación del territorio argentino- se fueron conformando diferentes tipos de pueblos para nuclear la mano de obra y sus familias, fortalecer el territorio, 
proteger las rutas comerciales, desarrollar la producción y conectar las regiones (Cansanello, 1998; Carrizo y Yuln, 2014). La conformación de cada pueblo (sea por el establecimiento de una capilla, una fábrica, una estación de ferrocarril), como señalaba Hardoy et al. (1988), nos permite conocer las historias políticas, económicas, culturales y sociales locales que forman parte de las historias nacionales.

Figura $\mathbf{N}^{\circ}$ 1. Localización de Azcuénaga, municipio de San Andrés de Giles, provincia de Buenos Aires.

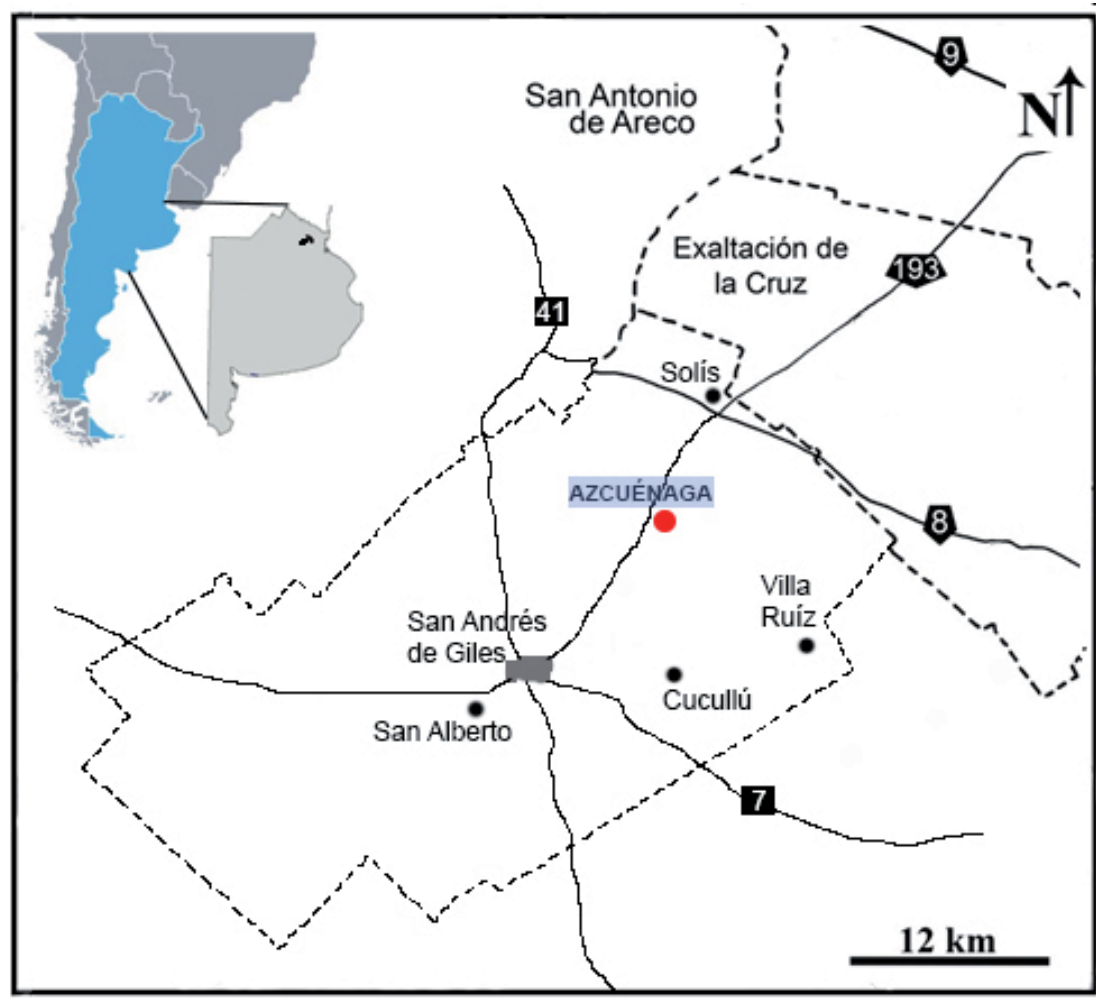

Fuente: elaboración propia.

Si nos remitimos a la historiografía local (AA.VV., 2005; García, 2000) la narrativa de Azcuénaga inicia en el siglo XVIII. Las tierras donde se asentó el pueblo fueron otorgadas por el gobernador del Río de la Plata -Brigadier Miguen de Salcedo- en 1740 a José Ruíz de Arellano ${ }^{9}$, quien dio parte de su propiedad a su cuñado -tras sus segundas nupcias con María Teodora de Suero y Giles- Francisco de Suero y Giles. Es en abril de 1880, con la llegada del ferrocarril en la zona, se construyó la estación. 
Las tierras aledañas a ella -que en ese momento se encontraban dentro de la estancia La Paloma del irlandés Juan Cunningham- fueron cedidas y loteadas por su dueño, dando lugar a la configuración del pueblo con 16 manzanas. El nombre que se le puso a la estación fue el que adoptaría el poblado en homenaje al General Miguel de Azcuénaga. Así, la instalación de la estación del ferrocarril incidió significativamente en la espacialización del pueblo en cuanto a qué terreno lotear y cómo diseñar la traza urbana (AA.VV., 2005): una avenida principal paralela a las vías del tren donde se ubicarían los principales comercios, que algunos de ellos dependían del ferrocarril como parte integral del proceso agroproductivo del área, como el transporte de cereal (Humacata, 2012). En cuanto a las instituciones, a comienzos de la década de 1880 , se trasladó a Azcuénaga la escuela rural Infantil Elemental №3 (en 1886 cambia a № 4). En 1902 se iniciaron las obras de la capilla Nuestra Señora del Rosario en tierras donadas por un miembro de la comunidad irlandesa, Mariana Mac Key de Cunningham. A su vez, en 1923 se creó el primer club, Apolo, y cuatro años más tarde se fundó el Club Recreativo. Ambos clubes se fusionaron en 1934 bajo el nombre Club Recreativo Apolo (García et al., 1998; Terrén, 1992). Asimismo, en 1936 se inauguró la ruta 7 que conecta San Andrés de Giles, por un lado, con la Ciudad de Buenos Aires, por el otro, con la provincia de Mendoza.

Azcuénaga fue un lugar en el que se registraron ciertas innovaciones dentro de lo que era el municipio. Además del establecimiento de la línea del Ferrocarril Central Argentino (posteriormente F.C. Gral. Bme. Mitre) que conectaba Luján con Pergamino y con la instalación de la estación que le dio origen en 1880; contó tempranamente con servicio de telefonía (1903), que le permitía comunicarse con la ciudad cabecera. Recién en diciembre de 1982 se pavimentó el camino que une Azcuénaga y la ciudad cabecera del partido (García, 2000); y en 1935 se incorporó el servicio eléctrico con ciertas limitaciones hasta que, en 1965 se conformó, por iniciativa local y con apoyo municipal, la Cooperativa de Electrificación y Tecnificación Agropecuaria de Solís y Azcuénaga Ltda., que posibilitó mejorar el servicio. Entre la década de 1930-40 se tecnificó la producción de pan con la adquisición de nueva maquinaria a cargo de la familia Rossi-Mitidiero en la panadería que aún funciona, La Moderna y que ya lleva cuatro generaciones en el oficio. En 1949 el Club logró adquirir un proyector móvil a batería que le permitía pasar películas además de ofrecer la presentación de radioteatros. Posteriormente, en la década de 1960 hizo su ingreso el televisor (AA.VV., 2005). Desde lo económico, Azcuénaga contaba con una variedad de comercios, como la sastrería, la panadería, fondas, carpintería, almacenes, como la casa Terrén (Humacata, 2012). Ésta última era un centro de acopio cerealero y almacén de ramos 
generales, siendo una fuente de trabajo importante para sus residentes. En Azcuénaga también se producían ladrillos, hasta la década de 1930, aunque actualmente es una actividad característica del pueblo de Cucullú. Asimismo, no se puede dejar de mencionar la actividad agraria en las estancias -ej. La Paloma o Santa Elena- y otros campos (AA.VV., 2005). En este marco, cabe señalar la relevancia social que tenía la familia Terrén y la señora Elena Ham, de la estancia Ham, como mecenas locales que contribuían en el financiamiento y organización de celebraciones y eventos, junto con el apoyo de otras familias que siempre terminaban siendo de alguna forma proyectos colectivos (AA.VV., 2005).

Cabe destacar que el municipio de San Andrés de Giles mantuvo un perfil agrícola-ganadero, donde predominó el cultivo de maíz, trigo y lino durante fines del siglo XIX hasta la década de 1970 (García, 1972). Entre 1995 y 1999 las proporciones en el ámbito productivo en el distrito se mantenían entre $70 \%$ y 30\% respectivamente, predominando el cultivo de soja, además de maíz, girasol, trigo y la ganadería bovina, porcinos y la cría de pollos (AA.VV, 1995-1999). Durante la década de 1990, en consonancia con los procesos de diversificación y pluriactividad del campo que comenzaron a emerger (en el marco de una apertura económica bajo la implementación de políticas neoliberales que llevó a la desregulación del agro y el cierre del servicio ferroviario), el municipio de San Andrés de Giles no fue una excepción. Como en otros municipios de la región, continuaron las actividades agrarias -con otras prácticas y tecnologías- a las que se incorporaron otras que se consolidaron en la década del 2000. Entre ellas, nos interesa destacar aquellos usos que no producen ni un bien ni un servicio, como ejemplo, la visita a una estancia o a un club de polo para comprar un caballo (González Maraschio, 2010). A todo ello, no hay que dejar de mencionar el proceso del deterioro del servicio ferroviario (que comenzó en la década de 1960) hasta su cierre definitivo en 1993. Estos procesos que impactaron tanto en el municipio como a nivel regional -los cuales fueron orientados por determinados actores políticos y económicos a pesar que ciertos relatos y discursos los despersonalicen-, tuvieron sus consecuencias locales en la vida cotidiana de Azcuénaga. Así, las nuevas formas productivas -que desplazaban a otras como la tambera- requerían menos empleados - quienes residían tanto en el campo como en el pueblo-, Ilevando a que algunos de los residentes dejaran Azcuénaga en busca de fuentes de trabajo en ciudades cercanas. A su vez, el cese del paso del tren ${ }^{10}$ no solo obstaculizó el traslado de los residentes para dirigirse a las ciudades a realizar compras, vistas y cumplir sus horarios de trabajo, sino que también incidió en la actividad comercial del pueblo. Al desactivarse un sistema productivo en el cual el tren promovía el transporte de granos, los locales aledaños a la estación dejaron de ofrecer el 
almacenamiento de los mismos. Las actividades comerciales de Azcuénaga fueron disminuyendo, llevando a cerrar algunos de sus locales, como la famosa Casa Terrén. La vida social del pueblo, como las actividades deportivas en el Club Recreativo Apolo, fueron cambiando su dinámica propia del lugar (Humacata, 2012; Hendel, 2015).

Estos procesos muestran cambios poblacionales que también incidieron en las dinámicas sociales de Azcuénaga. Si nos retrotraemos en el tiempo, el censo de 1869 muestra que San Andrés de Giles contaba con 3.820 habitantes. Esta cifra continuó en aumento hasta el 2010, en que alcanzó 23.027. Si observamos en las últimas tres décadas, en $1991 \mathrm{Az}-$ cuénaga contaba con 350 de 18.302 habitantes que había en el partido mientras que en 2001 ascendía a 357 (de 20.829) y en 2010 descendió a 312 (de 23.027). Como se puede observar la población en Azcuénaga se mantuvo estable, sin embargo, si se compara la población rural de la urbana en el municipio emerge otro panorama. En 1869, en San Andrés de Giles había 2.908 habitantes en la zona rural en contraposición a 912 de la zona urbana. Estos números continuaron en aumento, donde el área rural llevaba la delantera hasta 1960 donde se equipararon: 7.291 rural, 7.546 urbana. A partir de la década de 1970 aumenta la población urbana en detrimento de la rural, llegando al 2001 con 15.449 urbana y 5.443 rural (Hendel, 2015, p. 97). Estos datos coinciden con los recuerdos y percepciones de algunos residentes de Azcuénaga quienes advirtieron el cambio en las dinámicas sociales del pueblo a partir del despoblamiento del campo y del traslado de familias hacia las grandes urbes. Algunos de ellos señalan que una migración importante ocurrió en la década de 1960 debido a la instalación de frigoríficos y fábricas en Buenos Aires y el conurbano. Así, en la década de 1930 Azcuénaga era un centro comercial importante para la región, pero a partir de la década de 1960 comenzó disminuir su relevancia, tanto económica como sociocultural, deteriorándose con mayor fuerza en la década de 1990 (Hendel, 2015). Actualmente, muchos "jefes/as de familia" del pueblo tiene su trabajo en la ciudad de San Andrés de Giles, en otros casos su fuente laboral se mantiene en Azcuénaga, mientras que un tercer grupo trabaja en localidades de otros partidos como Luján, Mercedes, General Rodríguez o San Antonio de Areco. Sin embargo, de las familias que aún viven en el pueblo comentan que tiene algún pariente que sí tuvo que irse para poder sobrevivir o tener la posibilidad de estudiar -en institutos terciarios o universitarios- (Humacata, 2012).

Los cambios en el sistema de producción -lo que se producía, las tecnologías que se implementaban, la forma de transportar esa manufactura, las personas que se empleaban para las tareas, las relaciones que se establecían entre ellas y el lugar de trabajo y residencia, etc.- afectaron 
significativamente la dinámica social y económica de Azcuénaga y el entorno. A su vez, este tipo de pueblos que tuvieron su origen a partir del tren, no tuvieron su fin cuando cerró pero si afectó significativamente a la localidad al dificultar la movilidad de las personas dando la sensación de aislamiento (Sánchez, 2015).

\section{La valorización patrimonial y turística de Azcuénaga}

En la década de 1960 y de 1990 se produjeron procesos diferentes de tecnologización del ámbito rural. Estos incidieron en la forma de organizar la producción agraria, entre ellas, la necesidad de menos mano de obra. En este marco, la falta de fuentes de trabajo llevó a que muchas familias -o miembros de ellas- se desplazaran de sus pueblos o del campo como ocurrió en Azcuénaga y sus alrededores. Así, una de las postales más comunes -que aún se encuentran en la región- es lo que Faccio (2017) denomina "ruinas pampeanas". Es decir, lugares como las estaciones de ferrocarril, capillas y otras edificaciones que permanecen en un proceso de deterioro por el abandono. En términos de Santos ([1988] 2014), estaríamos frente a estructuras "viudas" y/o "ociosas ${ }^{11}$ " por su no utilización, que en muchos casos van adquiriendo nuevos contenidos, que pueden o no estar conviviendo con otras formas "vírgenes" que emergen para complementar nuevas demandas de alguna actividad que requiere otra infraestructura para desarrollarse. Esto permite indagar en las dinámicas pasadas y presentes.

En este marco, estructuras "viudas", "ociosas" o "ruinas pampeanas" comenzaron a ser reutilizadas, resignificadas y/o refuncionalizadas a partir de los procesos de patrimonialización. Así, no es casual que en el municipio de San Andrés de Giles a partir de la década de 1980 empezaran a formularse los primeros reconocimientos patrimoniales formales (Ordenanza 73 y 199/1988) a ciertas edificaciones que se mantenían como testimonios de esas dinámicas pasadas que le dieron "identidad" al pueblo en un determinado momento. De esta forma, lugares como las estaciones de ferrocarril o casonas antiguas fueron recontextualizadas y cambiaron su estatus de abandono y uso original para pasar a ser patrimonios culturales.

En Azcuénaga, una de las primeras declaratorias municipales se le otorgó a la estación de ferrocarril (Ordenanza 119; Decreto 398/1988) que le dio origen al pueblo. Posteriormente, se incluyó la Casa Terrén (Decreto Municipal 154; Ordenanza 20/1993), debido a sus "valores históricos, estéticos que implican un testimonio de la arquitectura, costumbres y entorno de una época de la localidad" (Decreto Municipal 154/1993). Así, preservar esta edificación "permitirá a toda la comunidad de Giles y en especial a la juventud, el encontrarse con sus tradiciones, su entorno y conservar una parte de nuestra historia" (Decreto Municipal 154/1993). 
Lugares del pueblo que en algún momento tuvieron ciertos usos, sentidos y funciones, pasan a configurarse como patrimonios culturales y posteriormente, como puntos de interés para el turismo. En particular, a comienzos del 2000, pos crisis económica, donde el turismo aparece como una alternativa económica y social de revitalización de los ámbitos rurales en Argentina (Guastavino et al., 2010) y en ese marco algunos residentes del municipio de San Andrés de Giles comenzaron a verlo como una oportunidad para los pueblos y parajes del distrito en el que Azcuénaga fue su primera experiencia:

Acá la gente del campo muchos tomaban créditos en los bancos, no podían pagarlos. Y terminaron (...) vendiendo su campo, su chacra, su quinta y (...) viviendo en una casita en la ciudad, gastándose los ahorros (...). Y en ese momento una persona que tenía una parcela justamente al lado de Azcuénaga (...) [quería] hacer el barrio cerrado o country. (...) me convoca a mí como arquitecto (...) y le propongo (...) no separar el pueblo viejo de lo nuevo. (...) Y yo de turismo, nada, no tenía ni idea, ni lo pensaba. Entonces de ahí empecé a ver el tema patrimonio, de la riqueza que tiene el pueblo y de ver cómo de ese proyecto urbanístico como involucrarlo y ponerlo en valor todo el pueblo (Asesor de turismo del municipio, residente de San Andrés de Giles, 2017).

Azcuénaga fue el primer ensayo de cómo comenzar a conformar los pueblos del municipio como atractivos turísticos.

Acá lo que falta es trabajo. Sino, la gente por ahí se quedaría. Trabajo en las zonas rurales. Por eso el tema de este de turismo hace unos doce años (...). Empezamos con nada. Porque esta era la sastrería de mi abuelo [actual restaurant] (...) y nos fuimos de a poquito poniendo en funcionamiento y bueno mis hijos fueron creciendo, estudiando. Son chefs los dos (...) el que está acá que ustedes vieron es el que hace todo. Yo colaboro en todo lo que puedo. (...) Y bueno con esto tratamos de que con la gente del pueblo se quede. Porque mi papá y mi mamá tenían la intención de vender la casa. (...) y bueno, ahora estamos en esto y ellos no se fueron y ellos están encantados. Ya hace doce años que estamos. (...) Siempre tratamos de que todo sea de acá. (...) Tratar de darle trabajo a la gente del pueblo. Es prioridad para nosotros (Docente jubilada, Azcuénaga, 2018).

Así, como la casa familiar fue refuncionalizada como restaurante para orientar un emprendimiento local, también buscaron generar fuentes de trabajo mediante la contratación de sus vecinos. En este tipo de iniciativas evocan recuerdos e historias a partir de los objetos que se encuentran en la casona, ofreciendo un servicio personalizado al contar la historia del lugar y del pueblo. Esto permite que los adultos mayores tengan una actividad y 
puedan socializar. Por lo tanto, el turismo, en este caso, no es solo un servicio que deja un rédito económico -cuando ocurre- sino que se presenta como una actividad social y colectiva. La participación de ciertos sectores de la comunidad contribuyó a que el pueblo fuera uno de los primeros en integrarse al Programa de la Secretaría de Turismo de la provincia de Buenos Aires denominado Pueblos Turísticos ${ }^{12}$, que se había inaugurado en el año 2008. Esto implicó nuevas recontextualizaciones, resignificaciones y refuncionalizaciones, especialmente de aquellos lugares que ya habían sido reconocidos formalmente como patrimonios locales ${ }^{13}$. Además de la refuncionalización de la sastrería en restaurant, otros emprendimientos también se fueron sumando. La Casa Terrén, luego de que descendientes de la familia recuperaron la propiedad, se reconvirtió en restaurant. Otras casas antiguas están siendo restauradas para ofrecer alojamiento, mientras que la capilla, la estación de tren, el galpón -estructura que se encuentra actualmente derrumbada por un temporal-, la panadería con horno a leña, la plaza, se presentan como los puntos de interés a visitar. A ello se incluye la promoción de las celebraciones locales, como la patronal que llegaba a convocar -antes de la pandemia por la COVID-19- cerca de 2000 personas. Para ofrecerlas como atractivos turísticos, se las "sacó a la calle" y se reorganizó las fechas para facilitar la participación de turistas. Asimismo, se incorporaron nuevos festejos, y de mayor envergadura, como la fiesta itinerante -de carácter provincial- de la "Galleta de Campo" (Humacata, 2012; Pérez Winter y Troncoso, 2019). El desarrollo turístico que se fue dando en Azcuénaga impulsó, además de la turistización en otros pueblos y parajes del municipio, el interés de mantener y cuidar los patrimonios locales (formalizados o activados) a través de jornadas con invitados especializados -como miembros de la Comisión Nacional de Monumentos, Lugares y Bienes Históricos-, y con la ampliación de reconocimientos formales propuestos desde la comunidad local (Pérez Winter, 2019). En este marco, podemos señalar un nuevo cambio de estatus o la adición de otro, el que ciertas casas, estaciones de ferrocarril, pulperías además de ser identificadas como patrimonio cultural pasaron a conformarse como atractivos turísticos, habilitando otro tipo de consumo. Como señala Prats ([1997] 2004), se pasa de un consumo interno a uno externo y mercantilizado.

Hasta aquí hemos hecho mención a los procesos de resignificación, recontextualización, cambios de estatus y singularización. Sin embargo, Kopytoff también planteaba la biografía de las cosas para dar cuenta de la mercantilización como proceso. Por lo tanto, ¿qué es lo que se mercantiliza desde el turismo en un pueblo? En primer lugar, el pueblo no se pone en venta -salvo excepciones- para desarrollar el turismo, sino que se configura como el espacio en el que se dan una serie de procesos de comerciali- 
zación de actividades y servicios asociados a esa práctica y que los actores que se involucran le otorgarán su particularidad. En este contexto es que, como ocurre en Azcuénaga, se refuncionalizan edificaciones para ofrecer gastronomía, alojamiento y actividades recreativas o se promueve la venta de productos locales -dulces, panes, chacinados, artesanías- mediante la organización de ferias durante los fines de semana-feriados o cuando se realizan las celebraciones locales. Pero para que todo esto pueda suceder, se necesita de la difusión de estas actividades y de imágenes que muestran al pueblo como un lugar atractivo para conocer. Asimismo, Kopytoff describe que existen esferas de intercambio como ámbitos diferenciales donde circulan y se intercambian determinadas mercancías, organizadas bajo diferentes valores de cambio. Para el tema que estamos abordando nos interesa hacer referencia, más que a esferas de intercambio, "esferas de circulación", donde circulan imágenes y representaciones que se comienzan a construir de un pueblo como turístico y que contribuyen a promover el proceso de mercantilización del mismo.

En esta última década proliferaron las imágenes -acompañadas de informaciones históricas y de servicios- sobre Azcuénaga en diferentes "esferas de circulación" -a las que antes no tenía acceso- para su promoción, como blogs (https://www.conocelaprovincia.com.ar/pueblos-turisticos/; http://pueblitos.com.ar/; https://mispueblosqueridos.blogspot.com/) y otras plataformas (TripAdvisor) y redes sociales ${ }^{14}$, folletos (Autor), libros (Vesco, 2018), producciones audiovisuales (Serie Pueblos de Buenos Aires), ferias de turismo (Feria Internacional de Turismo). De esta forma, proponemos que las "esferas de circulación" permiten posicionar y consolidar a los pueblos como atractivos. En este marco, nos interesa destacar el planteo de Harvey (2007): la paradoja del capitalismo que en el proceso de mercantilización, así como se tiende a homogeneizar los productos se busca particularizarlos. En ese sentido, Kopytoff señala que la cultura actúa como una forma de particularizar y sacralizar ciertos elementos para evitar su mercantilización o para singularizarlos. Así, aquellos actores involucrados en la promoción y el marketing destacarán las particularidades del pueblo, mediante las imágenes fotográficas y representaciones que de él se construyan acompañados de discursos (Pérez Winter y Troncoso, 2019). En el caso de Azcuénaga, tanto la folletería del área de turismo del municipio como la del programa Pueblos Turísticos de la Secretaría de Turismo de provincia de Buenos Aires, la representan con una foto donde se visualiza la estación de tren o la capilla. Estas son las imágenes que se construyen de la Azcuénaga turística y suelen ser las que luego los visitantes tratan de reproducir. Por otra parte, si pensamos en el turismo, quienes se involucran en la configuración de atractivos y destinos turísticos no solo intentan crear un "producto" tangible auténtico y único mediante su singularización, sino 
que también buscan vender lo intangible desde las "experiencias". En este sentido, es frecuente encontrar que la publicidad que promociona a los pueblos presentan eslóganes como "viví Pueblo" (Folletería de San Andrés de Giles, 2017).

Por último, es interesante señalar que no todo el pueblo -por más pequeño que sea- se consume turísticamente. Generalmente, el área central -plazas, estaciones de tren, costaneras, etc.- son las que se difunden en las "esferas de circulación", las que cambian de función (Santos, [1988] 2014), como atractivos durante los fines de semana y feriados. Estos nuevos estatus y usos/funciones de los lugares tienden a generar fricciones entre residentes y entre residentes y visitantes debido a que los primeros precisan cambiar sus comportamientos para brindar mejor atención a los segundos. Además, los lugares son reapropiados y resignificados tensionándose los diferentes sentidos que la comunidad local otorga a ciertos lugares locales en contraposición a los nuevos consumos que genera la llegada de turistas.

\section{Consideraciones finales}

Los pueblos rurales de la provincia de Buenos Aires poseen diversas trayectorias vitales. Las transformaciones que fueron ocurriendo en esas localidades en las últimas décadas, que dan lugar a pensar en las "nuevas ruralidades", contribuyeron a generar crisis económicas y socio-culturales de los ámbitos rurales. Todos estos eventos incidieron significativamente al punto que varios municipios debieron buscar alternativas para dinamizar sus localidades. Así, el turismo emergió como una posibilidad. De esta forma, un pueblo puede ser la confluencia de diversos circuitos productivos -agrario, minero, etc.- en el que podemos agregar al turismo, como se analizó en el caso de Azcuénaga.

Desde esa práctica ocio-recreativa actores estatales y no estatales seleccionaron y valorizaron ciertos elementos -como aquellos identificados como patrimonios (formales o activados), tales como las estaciones ferroviarias, los paisajes agrarios y las festividades- en detrimento de otros o se impulsó la conformación de nuevas festividades, por ejemplo. Estos procesos de valorización de lugares, prácticas, objetos y sujetos asociados a lo rural crean y configuran "identidades turísticas" para cada pueblo con el propósito de incorporarlos como productos auténticos y singulares dentro del mercado. Sin embargo, estas iniciativas promueven representaciones idealizadas de los ámbitos rurales que maquillan e invisibilizan ciertas historias y carencias que el turismo no logra resolver.

Por otra parte, un lugar, como sostiene Santos ([1988] 2014), es un conjunto de elementos que tienen autonomía de existencia por las cosas 
que lo forman: calles, electrificación, industrias, restaurantes, edificios, etc., pero que no tienen autonomía de significación, porque todos los días nuevas funciones sustituyen las antiguas, nuevas funciones se imponen y se ejercen. A su vez, los pueblos pueden estar atravesados por mutaciones funcionales, pero ellas no necesariamente deben ocurrir simultáneamente. En Azcuénaga el turismo no funciona todo el tiempo en todo el pueblo, sino que sucede los días no hábiles y en determinadas áreas. Por lo tanto, como señala Santos, pueden darse cambios estructurales cuando emerge una relación entre la estructura socio-económica y la estructura socio-económica y política. Alteraciones de viejas formas para la adecuación de nuevas funciones. La implementación del turismo puede generar transformaciones estructurales al generarse políticas e iniciativas que reestructuran ciertos ámbitos para desarrollar esta práctica como los que comentamos a lo largo de este artículo.

Ante el desarrollo de todos estos procesos de recontextualizción, resignificación y refuncionalización, los pueblos terminan siendo un palimpsesto de sentidos y funciones diversos en el que conviven formas "viudas" y "vírgenes". Ello no solo produce cambios en el espacio sino también en los vínculos, en las relaciones entre quienes viven en el pueblo y quienes lo consumen. Como señala Massey (1994) no todos experimentan sentidos de pertenencia -o lo construyen- de la misma manera y este va variando a través del tiempo. A su vez, esos sentidos de pertenencia no se configuran solo con elementos locales sino con elementos e imaginarios globales. $Y$ en ese proceso las geometrías de poder no se dejan de lado, sino que se reproducen y tensionan.

Massey (1995) también sostiene que a veces existe una dislocación entre el lugar, el pasado y el presente. Es decir, los lugares son híbridos, están compuestos de relaciones, conexiones que, con el tiempo, algunas de ellas se han establecido, moldeado, produciendo algo nuevo pero que en el presente pensamos que es algo es viejo, que quedó fijado. Y las nuevas "intrusiones" -las que no nos agradan- se perciben como una invasión, algo que está fuera de lugar. Por lo tanto, los lugares son siempre construidos a partir de articulaciones de relaciones sociales. Y lo que se reconoce como su "unicidad local" es siempre un producto de amplios contactos. Lo local es siempre producto en parte de fuerzas globales, mientras que lo global en este marco se refiere no necesariamente a una escala planetaria sino más allá de ese ámbito. Sin embargo, "el pasado" es visto en algún sentido como la corporización del verdadero carácter del lugar. Estos tipos implícitos y explícitos de internalización y construcción esencialista del carácter del lugar, no solo fracasa en reconocer una larga historia de interconexiones con otros lugares, sujetos y objetos, ellos además presuponen una relación particular entre una identidad asumida 
del lugar -que puede ser reconstruida y difundida desde el turismo- y su historia. Sin embargo, los pasados de un lugar están abierto a múltiples lecturas y prácticas/procesos generados desde el presente y que pueden legitimar, tanto la versión de pasado que se selecciona como el presente en el que se está posicionado.

\section{Referencias bibliográficas}

AA.VV. (1995-1999). Revista Primer plan quinquenal. San Andrés de Giles: Municipalidad de San Andrés de Giles.

AA.VV. (2005). Historias de Azcuénaga. Historias que nos trae el tiempo. Azcuénaga: Municipalidad de San Andrés de Giles.

Cansanello, O. (1998). Pueblos, lugares y fronteras de la provincia de Buenos Aires en la primera parte del siglo XIX. Jahrbuch für Geschichte Lateinamerikas, 35, 159-187.

Carrizo, S. y Yuln, M. (2014). Patrimonio arquitectónico en perspectiva geohistórica: la territorialización del noroeste de la provincia de Buenos Aires. Eure, 40(120), 73-90. https://ri.conicet.gov.ar/ handle/11336/33466.

Castro, H. y Zusman, P. (2016). Debates y derivas sobre la ruralidad contemporánea. Reflexiones desde el campo pampeano. En J. Blanco y S. Lencioni (Eds.), Lo rural y lo urbano en Argentina y Brasil. Geografías materiales y conceptuales en redefinición ( $p p$ 281-308). Río de Janeiro: Consequência.

Cloquell, S. (Ed.) (2014). Pueblos rurales. Territorio, sociedad y ambiente en la nueva agricultura. Buenos Aires: Ciccus.

Douglas, M. \& Isherwood, B. ([1979] 1990). El mundo de los bienes. Hacia una antropología del consumo. Buenos Aires: Giralbo.

Faccio, Y. (2020). Los grandes valores que hicieron grande al país están en los pueblos: La ruralidad según dos ONG al rescate de pueblos irurales? argentinos. Latitude, 14(2), pp. 106-134. https://www.seer.ufal.br/index. php/latitude/article/viewFile/6500/pdf.

Fernández, C. (2017). Teatro comunitario argentino y potencialidad política. El caso del teatro comunitario de Rivadavia. Escritos, 25(54), 165-196. https://revistas.upb. edu.co/index.php/escritos/issue/view/16.

Garavaglia, J. C. (2009). San Antonio de Areco, 1690-1880. Un pueblo de la campaña, del Antiguo Régimen a la modernidad. Rosario: Prohistoria.

García, S. (1972). Historia de San Andrés de Giles. (Desde sus orígenes hasta 1930). San Andrés de Giles: Municipalidad de San Andrés de Giles.

García, S. (2000). Historia de San Andrés de Giles 1930-1980. San Andrés de Giles: Biblioteca Popular Alberdi.

García, S., León, G. y Terrén, H. (1998). Efemérides gilenses. San Andrés de Giles: Municipalidad de San Andrés de Giles.

González Maraschio, F. (2010). Actividades y pluriactividades en establecimientos rurales agropecuarios y no agropecuarios. El caso de San Andrés de Giles. VI Jornadas de Sociología de la UNLP, 1-23. https://www. aacademica.org/000-027/800.

Hardoy, J. E., Madrea, L., Tartarini, J. (1988). Pequeños poblados históricos: Conservación y rehabilitación integral. DANA, 25, 92-107.

Hendel, V. (2015). Síntomas de una ausencia. Acerca de la experiencia contemporánea de lo rural en la región pampeana bonaerense. El caso de San Andrés de Giles (20072013). Tesis doctoral. Facultad de Ciencias Sociales: UBA.

Hiernaux, D. (2002). Turismo e imaginarios. En Imaginarios sociales y turismo sostenible (pp. 7-36). Costa Rica: FLACSO.

Humacata, L. (2012). Nuevas valorizaciones del territorio rural: ¿Azcuénaga, de la 
vida agropecuaria a paisaje turístico? En: $2^{\circ}$ Jornadas Nacionales de Investigación y Docencia en Geografía Agraria y $8^{\circ}$ Jornadas de Investigación y Extensión del Centro de Investigaciones Geográficas (JCIG). Facultad de Ciencias Sociales UNICEN (Tandil). Recuperado en: https://jornadascig.wixsite. com/jornadascig/copia-de-eje-c.

Kopytoff, I. (1986). The cultural biography of things: commoditization as process. En A. Appadurai (Ed.), The social life of things: commodities in cultural perspective (pp. 89122). Nueva York: Cambridge University Press.

Massey, D. (1994). Space, Place and Gender. Minneapolis: University Press.

Massey, D. (1995). Places and their pasts. History of Workshop Journal, 39, 182-192.

Massey, D. (2012). La filosofía y la política de la espacialidad. Algunas consideraciones. En A. Albet, N. Benach \& D. Massey, Un sentido global del lugar (pp. 157-181). Barcelona: Icaria.

Pérez Winter, C. (2018). Patrimonio y procesos de patrimonialización de dos "pueblos" de la provincia de Buenos Aires (Argentina). Buenos Aires, Argentina: Editorial de la Facultad de Filosofía y Letras Universidad de Buenos Aires.

Pérez Winter, C. (2019) El "retorno al campo" desde la mirada local. Redescubriendo los atractivos patrimoniales pampeanobonaerenses (Argentina). Revista Pasos, 17 (4), 779-793.

Pérez Winter, C. (2020). Aportes teóricos para la indagación del patrimônio cultural. Patrimônio e Memória, 16(2), 563-590.

Pérez Winter, C. y Troncoso, C. (2019). La imagen turística del campo pampeano bonaerense (Argentina) a través de la promoción oficial. Cuadernos de Antropología, 50, 85-106.

Prats, L. ([1997] 2004). Antropología y patrimonio. Barcelona: Ariel.

Ratier, H. (2009). Pueblos rurales. Buenos Aires: La Colmena.
Sánchez, J. (2015). Despoblamiento de pequeñas localidades argentinas ies responsable el tren? Documentos de Trabajo del Instituto del Transporte, 5, 2-84. http://www. unsam.edu.ar/.

Santos, M. [1988], 2014. Metamorfoses do espaço habitado, fundamentos Teórico e metodológico da geografia. Hucitec: São Paulo.

Terrén, H. (1992). El consejo escolar de San Andrés de Giles. Sus orígenes (1875-1910). San Andrés de Giles: Biblioteca Popular AIberdi.

Vesco, L. (2018). Desconocida Buenos Aires. Secretos de una provincia. Buenos Aires: Ateneo.

Zusman, P. y Pérez Winter, C. (2018). Las áreas rurales y el patrimonio histórico-cultural. En: Castro, H. y Arzeno, M. (Eds.), Lo rural en redefinición. Aproximaciones y estrategias desde la Geografía (pp. 231-252). Buenos Aires: Biblos.

\section{Notas}

1 Cecilia Pérez Winter. Investigadora del CONICET. Doctora en Antropología Social por la UBA. Este trabajo forma parte del proyecto La activación de elementos identitarios desde los proyectos estatales de turismo rural (PICT 2017-2567). Investigadora del CONICET. Doctora en Antropología Social por la UBA. Este trabajo forma parte del proyecto La activación de elementos identitarios desde los proyectos estatales de turismo rural (PICT 2017-2567).

2 Entendemos al patrimonio en sentido amplio (inmueble, mueble, natural, cultural, material e inmaterial). Consideramos que se construye socialmente, aunque existen actores que suelen participar más que otros. Sin embargo, diferenciamos entre aquellos patrimonios que son activados -de alguna forma mediante la exhibición de un museo, una obra de teatro, un festejo o conmemoración- de aquellos que son reconocidos 
formalmente mediante alguna normativa o declaratoria (Pérez Winter, 2020).

3 En Argentina los pueblos rurales son aquellos que poseen menos de 2.000 habitantes. Algunas investigaciones 0 políticas públicas también mencionan que estos deben tener alguna vinculación con la actividad agraria aunque sus características son más diversas y complejas (Cloquell, 2014).

4 Estos programas suelen inspirarse en propuestas ya implementadas en otros países como: de Europa, II Piu Borghi en Italia; Les Plus Beaux Viilages en Francia, Los pueblos más bonitos en España y de América Latina, Pueblos mágicos en México, Red Turística Pueblos Patrimonio en Colombia.

5 Consideramos relevante recuperar el enfoque propuesto por Kopytoff ya que indaga nos permite indagar, desde una perspectiva cultural procesos que en apariencia parecerían ser predominantemente económicos. Analizar la mercantilización de los pueblos desde una "biografía cultural" nos permite dar cuenta de otros aspectos, no solo materiales, sino también simbólicos, haciendo visible la complejidad de estos procesos.

6 Concordamos con aquellos/as autores/ as que definen al turismo, desde una mirada crítica, como una industria económica pero también como práctica socio-cultural de construcción social. Es decir, que ciertos actores, tanto de países emisores como receptores, participan de la conformación y promoción de ciertos lugares, prácticas, objetos como atractivos o destinos turísticos. Los procesos de desarrollo turístico son dinámicos y no están exentos de tensiones y conflictos ya existentes en el territorio o que emergen a partir de su implementación.

7 Aunque existen programas e investigaciones que muestran cada vez más la participación activa de las comunidades locales en la orientación de emprendimientos comunitarios turísticos, en algún punto del proceso es frecuente encontrar un "experto" -hasta dentro del propio ámbito de la comunidad-que actúa como mediador (Gallo y Peralta, 2018).

8 En algunos casos, se configura, en términos de Harvey (2007), como una "renta monopólica", de manera directa, a través de la comercialización del recurso o lugar mismo, o indirectamente, a través de un servicio asociado a él.

9 Garavaglia (2009: 22) señala que Arellano compró tierras pertenecientes al capitán Roque de San Martín, un vizcaíno asentado cerca del río Luján. Sin embargo, García (1972, 2000: 8) y Burgueño (1927) presentan algunas discrepancias.

10 Mientras el servicio ferroviario dejaba de funcionar, comenzaba a expandirse la red de rutas y autopistas a partir de 1997. En ese marco, se asfalta el camino de ingreso a Azcuénaga que permite a sus habitantes generar otra forma de traslado y hacia otros lugares (Hendel, 2015: 118). Sin embargo, el uso de esas vías requiere de otros recursos para poder aprovecharlas. El tren era una forma más fácil, confiable y económica de movilizarse.

11 Esos términos de "viudas" y "ociosas" están haciendo referencia a aquellas estructuras que quedaron en desuso y/o abandonadas por el cambio en las formas productivas pero que pueden ser refuncionalizadas mediante otras prácticas. Así, una estación de ferrocarril abandonada puede ser reutilizada como centro cultural como ocurre en la localidad de Carlos Keen en el municipio de Luján (Santos, ([1988] 2014).

12 El programa se presenta como una estrategia comunitaria para el desarrollo local para pequeñas localidades no urbanas y de menos de 2.000 habitantes. En la primera etapa de implementación (2008-2009) se incorporaron seis pueblos, incrementándolos en los años sucesivos hasta contar con un total de 31 en 2019. Es a partir de este programa que el pueblo de Azcuénaga se consolidó como atractivo turístico del municipio y de la provincia. 
13 Entendemos al patrimonio en sentido amplio (inmueble, mueble, natural, cultural, material e inmaterial). Consideramos que se construye socialmente, aunque existen actores que suelen participar más que otros. Sin embargo, diferenciamos entre aquellos patrimonios que son activados -de alguna forma mediante la exhibición de un museo, una obra de teatro, un festejo o conmemoración- de aquellos que son reconocidos formalmente mediante alguna normativa o declaratoria (Pérez Winter, 2020).

14 La tecnología también juega un rol en el proceso de mercantilización. Los medios de comunicación, como internet, junto la creación de aplicativos que buscan una mayor interacción y acceso a información y gestionar viajes con cierta autonomía son elementos que inciden en las estrategias de promoción y posicionamiento de atractivos/destinos turísticos. 